\title{
SIMULATION OF MAGNETIC SYSTEM OF APPARATUS OF MAGNETIC WATER TREATMENT FOR BOILER GREENHOUSE PRODUCTION
}

\author{
Sergey Antonov, Gennady Nikitenko, Andrey Adoshev, Igor Devederkin, Sergey Dorozhko \\ Stavropol State Agrarian University, Russia \\ antonov_serg@mail.ru,nikitenko_gv@mail.ru, adoshev@mail.ru, devederkin@mail.ru, \\ dev6307@yandex.ru
}

\begin{abstract}
For agricultural enterprises specializing in the cultivation of greenhouse vegetables, one of the problems is deposition of salts on the surfaces of the heat exchange equipment. The amount of these salts depends on their content in the water used for this. A layer of scale of one millimeter leads to excessive fuel consumption for heating water up to $10 \%$. The main way to combat the deposition of salts is chemical. This method is effective, but it has a strong environmental impact. Least of all the environment is affected by physical methods. Of all the physical methods, the most promising method is magnetic exposure to water. Analysis of the existing designs of magnetic water treatment devices revealed their shortcomings. The main disadvantage is the presence of a narrow gap, in which the treatment with a magnetic field of water takes place. This gap contributes to reduced performance and reliability during operation. The proposed apparatus makes it possible to eliminate this drawback by using magnetic scattering fluxes when treating water. Water treatment with a magnetic field occurs throughout the cross section of the impact zone, which is similar to the cross section of the supply pipe. The modeling of the apparatus is carried out using modern computer programs based on the finite element method. The main task in streamlining the design of the magnetic system of the apparatus is to obtain maximum values of magnetic induction in the water treatment zone. The mechanism of action of a magnetic field on water is not fully understood. Each new device should undergo experimental research on the effective effect on water.
\end{abstract}

Keywords: magnetic field, magnetic system, energy saving, greenhouse, coolant.

\section{Introduction}

Maintaining the temperature conditions of industrial greenhouses is carried out from centralized boilers. Analysis of the technical condition of heating boilers and heating networks has shown that they are operated in violation of the requirements of safety rules and technical maintenance [1;2]. The main problem is the untimely descaling of the surfaces of boilers and heat networks (Fig. 1). Scale has a low thermal conductivity, therefore, it reduces the transfer of heat to the heated water. The deposited scale contributes to an increase in fuel consumption for water heating.

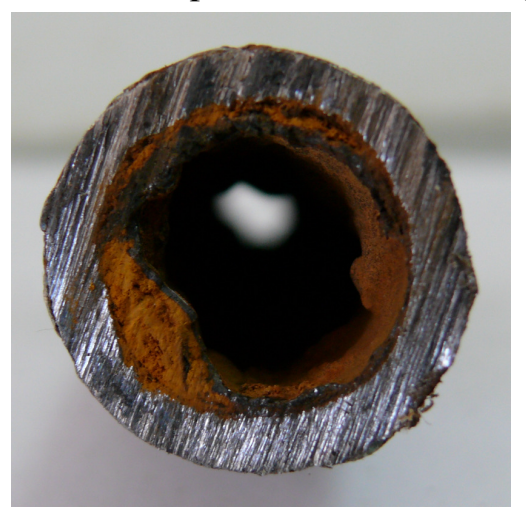

Fig. 1. Piping section with scale deposit

Salt deposition in pipelines reduces their service life. The use of chemical methods of water treatment is effective, but it requires special measures to meet the requirements of environmental safety. Given the above, the physical methods of water treatment become important. Analysis of the physical methods of water treatment showed that the most effective is the magnetic treatment of water. There are a large number of devices for magnetic water treatment of both Russian and foreign manufacturers.

For example, a device for magnetic water treatment MWS (MПВ) is known, which is intended for magnetic water treatment in a stream with a constant magnetic field to prevent the formation and elimination of already deposited scale on the walls of pipelines and heat exchange elements (Fig. 2). 
a)

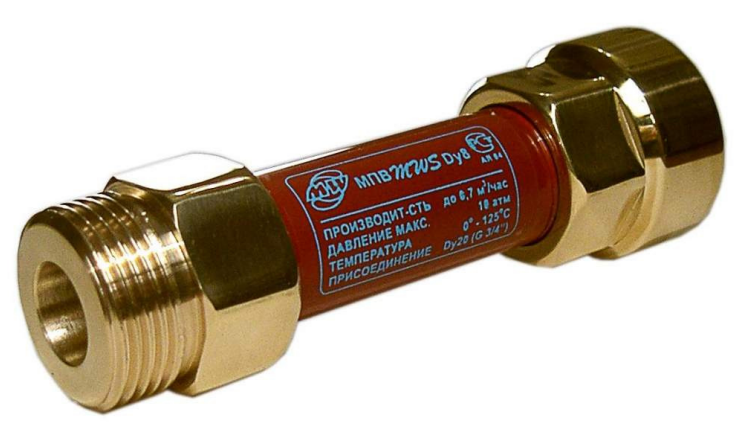

b)

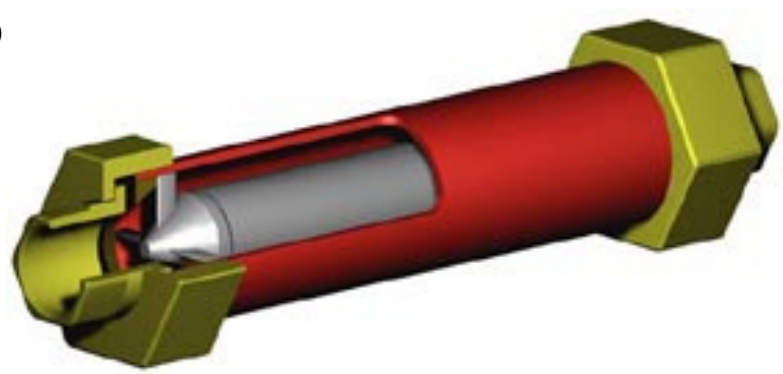

Fig. 2. Magnetic water converter MWS (MПB): a - appearance; b - in section

The device of magnetic water treatment AMO-25 is intended for anti-scale magnetic treatment of water circulating through the heat exchange equipment of heat points and used for hot water supply (Fig. 3).

The principle of AMO-25 operation is based on the effect of a magnetic field of certain intensity on carbonate salts rigidity dissolved in water.

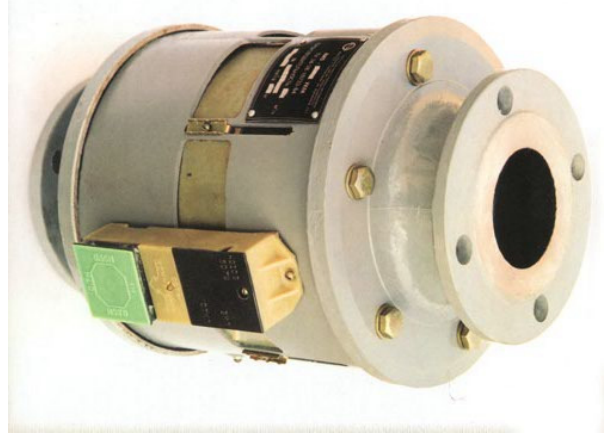

Fig. 3. Magnetic water treatment apparatus AMO-25

The designs of the devices are different, they depend: on the purpose, performance, method of obtaining a magnetic field, number of processing zones and the peculiarity of technical solutions. However, there are a number of disadvantages that limit their applicability. The main disadvantage is a narrow gap in which water treatment takes place.

\section{Materials and methods}

There are many devices for magnetic water treatment. The construction of these devices has significant deficiencies: design complexity; magnetic systems are ineffective per unit of mass and power; low productivity, due to the small cross section for the passage of a substance; low-tech, in the manufacture, and the labour consumption for assembly [3;4].

The proposed apparatus (Fig. 4) eliminates the listed disadvantages. It contains: body (1) (left side) and (6) (right side), frame of the magnetizing coil (2), between the two halves of the body (1) and (6) to seal the magnetizing coil (3) from moisture, rubber gaskets (4) and (5). Flanges (7) are welded on to the outside bodies (1) and (6), if necessary, when installing the device on the pipeline. The frame of the magnetizing coil in axial section has a thin wall. In order to increase or decrease the value of the magnetic induction in the treatment area, it is necessary to change the length of the thin wall.

The device works as follows. When applying alternating or direct current to the magnetizing coil 3 , the magnetic flux $\Phi$ (Fig. 5) is formed, the power lines of which are closed along the body 1, 6 and the frame 2 . The thin wall of the frame 2 operates in saturation mode and represents a significant magnetic resistance for the magnetic flux $\Phi$, which is divided into: $\Phi_{1}$ is the magnetic flux, closed on the thin wall; $\Phi_{2}$ is the magnetic flux in the volume of the magnetizing coil; $\Phi_{3}$ is the magnetic flux, buckling in the direction of the treated water. 


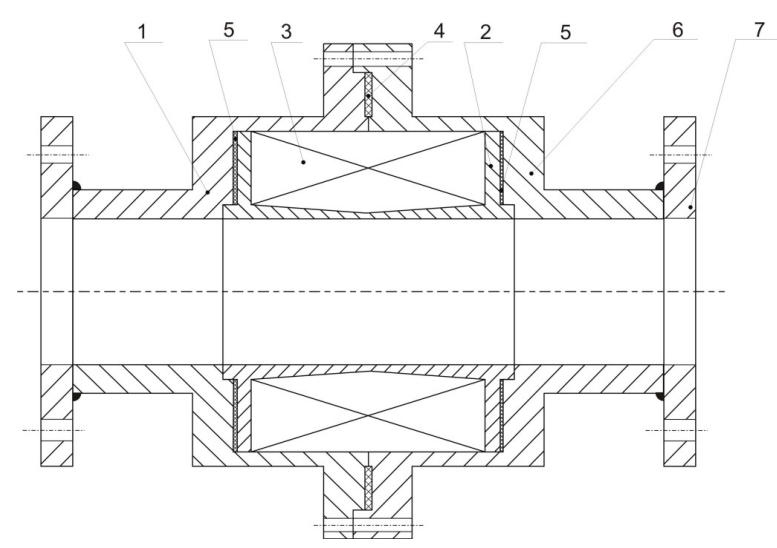

Fig. 4. Magnetic water treatment apparatus: 1 - body (left side); 2 - frame of the magnetizing coil; 3 - magnetizing coil; 4 - rubber gasket; 5 - a rubber gasket; 6 - body (right side); 7 - flange

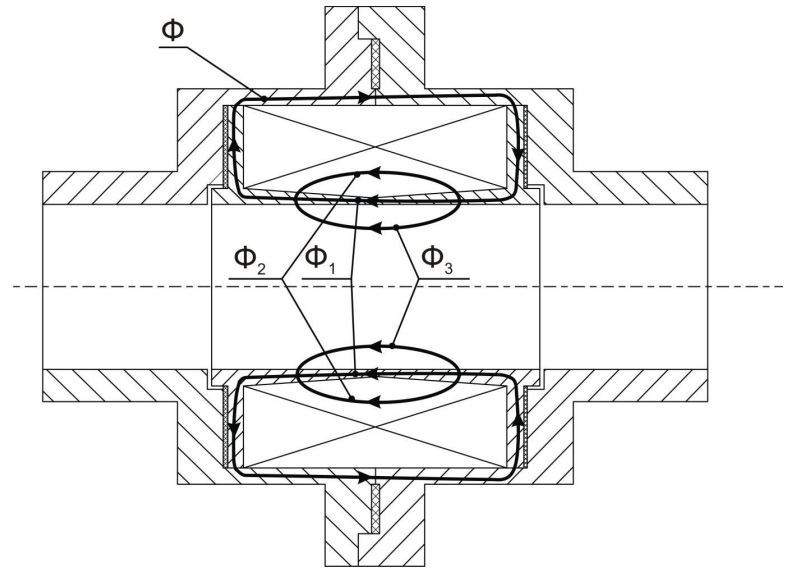

Fig. 5. Operation principle of magnetic water treatment apparatus

Water moving through the pipeline at a certain speed repeatedly crosses the lines of the magnetic flux $\Phi_{3}$ and is exposed to physical impact. Unlike the existing apparatus designs, the proposed magnetic water treatment apparatus simplifies sealing the winding from the treated water, since the base of the magnetizing coil 3 is the metal frame 2. The method of forming the working magnetic flux (by saturating the thin wall of the frame) is fundamentally changed. In addition to all the above, you can vary the active zone of the workflow buckling. Unification of the device allows with the same case, by replacing the frame 2 with the magnetizing coil 3, to choose the optimal parameters of the magnetic field for any technological process.

The effect of water treatment with a magnetic field depends on the devices parameters and the properties of water: magnetic induction; tension gradient in the gap apparatus; water flow rates; exposure time of the magnetic field; number of the magnetic field intersections; salt concentrations; amounts of aggressive carbon dioxide [5;6].

When designing new devices, it is necessary to calculate them for compliance with certain criteria. Accounting for these criteria will allow reducing the consumption of apparatus non-ferrous alloys or non-ferrous metals by $1 \mathrm{~m}^{3} / \mathrm{h}$ of water consumption [7].

The main criterion for the optimal apparatus is the provision of a certain value of the structural module $\mathrm{M}$ in the treatment zone. This indicator is the product of the apparatus magnetic induction, the rate at which the water crosses the magnetic field and the time the water stays in the treatment zone (1).

$$
M=B_{\mathrm{a} v} \cdot v \cdot t .
$$

where $M$-constructional module, $\mathrm{T} \cdot \mathrm{m}$;

$B_{a v}$ - average magnetic induction, $\mathrm{T}$;

$v$ - fluid flow rate, $\mathrm{m} \cdot \mathrm{s}^{-1}$;

$t$ - finding time of liquid in the magnetic field, s. 
For the systems with fluid flow rate it is possible to accept a constant equation (2):

$$
M=B_{\mathrm{av}} \cdot L_{0} .
$$

where $L_{0}-$ water way to processing zone, $\mathrm{m}$.

Based on the data of [3;8], we can say that the processing will be effective at values $M=0.2 \ldots 2.0$ $\mathrm{T} \cdot \mathrm{m}$. The use of this criterion by designers allows them to vary the values of magnetic induction and the width of the treatment zone (Fig. 6.) to determine the optimal design of the device, while maintaining the specified value of the construction module.

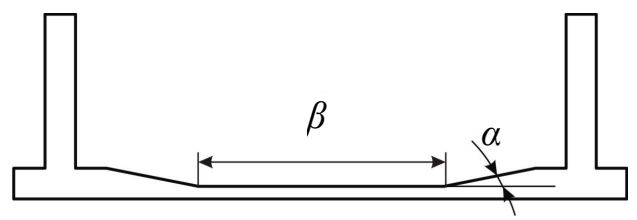

Fig. 6. Shape of magnetic system poles

The value of the structural module $(M)$ is influenced by the following parameters of the apparatus: length of the thin shunt wall $(\beta)$ of the magnetizing coil frame; bevel angle $(\alpha)$ of the magnetizing coil frame.

\section{Results and discussion}

To calculate the magnetic system of the device, we use the ELCUT software package (the calculation of two-dimensional fields by the finite element method). The program allows to solve flat and axisymmetric problems. As a result of the calculation, we obtain a picture of the magnetic fluxes distribution (Fig. 7).

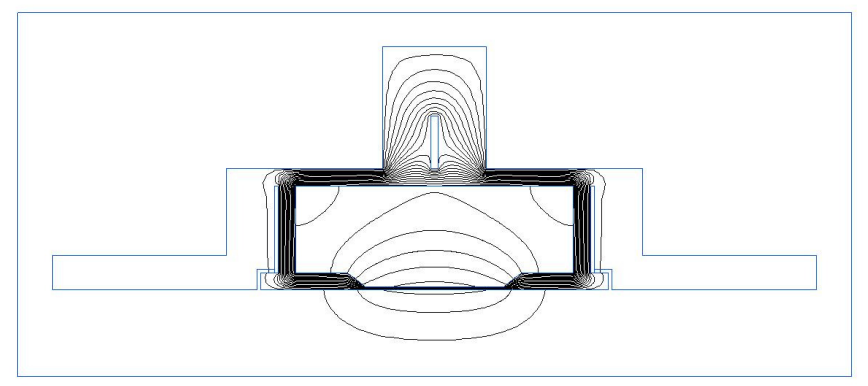

Fig. 7. Calculation result of magnetic system of magnetic water treatment apparatus

To analyze the parameters of the magnetic system, it is necessary to construct graphical dependencies of the structural module $(M, \mathrm{~T} \cdot \mathrm{m})$ on the contour line along the wall $\left(\mathrm{L}_{1}\right)$ and on the axis of symmetry $\left(\mathrm{L}_{2}\right)$ (Fig. 8).

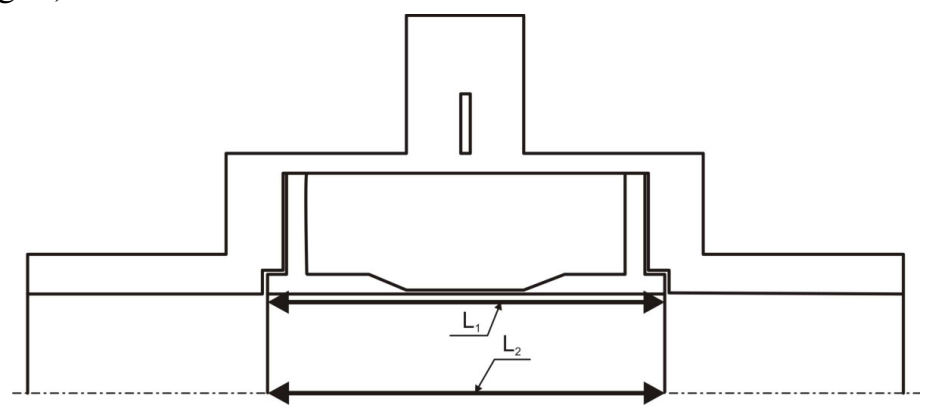

Fig. 8. Contours for building construction module

After analyzing the obtained graphical dependences, it should be noted that the maximum value of the structural module both along the wall and on the axis of symmetry is more than $3.8 \mathrm{~T} \cdot \mathrm{m}$. The minimum value in both cases is at least $3.6 \mathrm{~T} \cdot \mathrm{m}$. The obtained parameters of the structural module show that water treatment with a magnetic field will be effective. 
a)

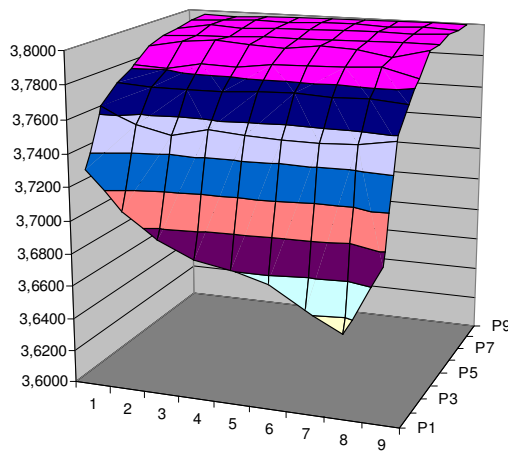

b)

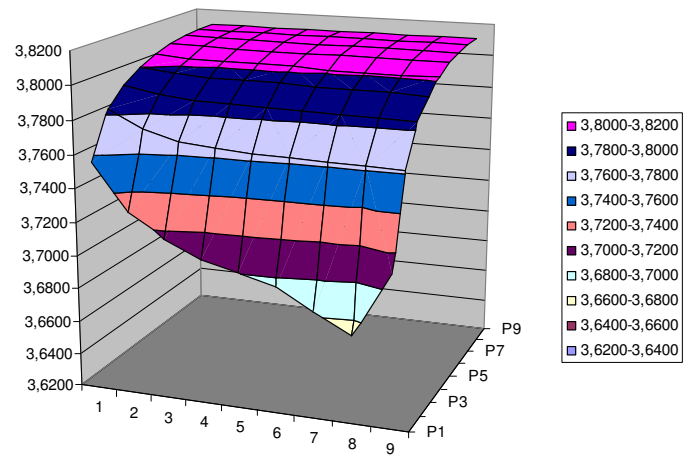

Fig. 8. Value of structural module $(M)$ as function of bevel angle ( $\alpha$ from 1 to 9 ) and length of thin shunt wall ( $\boldsymbol{\beta}$ from P1 to P9): $a$ - along the wall; $b$ - on the axis of symmetry

\section{Conclusions}

Analyzing the obtained results, it can be concluded that the magnetic flux, when using a thin shunt wall, is pushed towards the treated water. The magnitude of the maximum value of magnetic induction depends on the length of the thin wall - the longer the length of the thin shunt wall, the smaller the value of the maximum magnetic induction in the working area. The size of the structural module, on the contrary, is larger, the larger the thin wall.

\section{References}

[1] Diamant R.M.E. Magnetic water treatment/-"J. Fuel and Heat/ Tehnics”, 1969, №16, pp. 24-26

[2] Boiler scale reduced by magnetic treatment. - "Design and Components in Engineering", 1965, №8, p.12.

[3] Антонов С.Н. Аппараты магнитной обработки воды. Проектирование, моделирование и исследование (Magnetic water treatment apparatus. Design, modeling and research) : monograph / S.N. Antonov, A.I. Adoshev, I.K. Sharipov, V.N. Shemyakin. - Stavropol: AGRUS Stavropol State. Agricultural University, 2014. - 220 p. (In Russian)

[4] Антонов С. Н., Ивашина А. В. Аппарат магнитной обработки воды (Magnetic water treatment apparatus ). Mechanization and electrification of agriculture, №8, 2009, pp. 31-32. (In Russian)

[5] Rubin A. J. "To Determine if Magnetic Water Treatment is Effective in Preventing Scale," Ohio State University, 1973. 123 p.

[6] Antonov S.N., Gabriyelyan S.Z., Mastepanenko M.A., Zorina E.B., Nozdrovicky L The device of magnetic processing of water for boiler greenhouse. Research in agricultural engineering. Vol. 62, 2016, Special Issue: pp. 27-33.

[7] Rippie C.W. Process and apparatus for magnetic treatment of gaseous oxygen. Patent US, Int. Cl. 204-155, №3186929, date of publ. 01.06. 1965.

[8] Kuivinen D.E., "Comparing Corrosion Rates of Steel Corrosion Coupons in Magnetically Treated Water and in a Water System Utilizing Corrosion Inhibitors," National Aeronautics and Space Administration, Lewis Research Center, Cleveland, 1975. 135 p. 